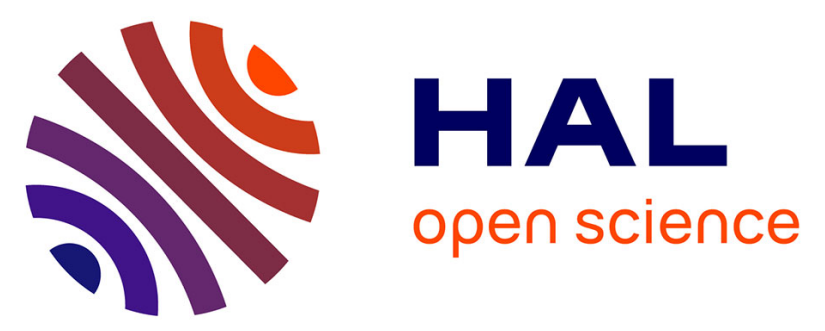

\title{
Effect of carbon nanotubes on the in-plane dynamic behavior of a carbon/epoxy composite under high strain rate compression using SHPB
}

Manel Chihi, Mostapha Tarfaoui, Yumna Qureshi, Chokri Bouraoui, Hamza Benyahia

\section{To cite this version:}

Manel Chihi, Mostapha Tarfaoui, Yumna Qureshi, Chokri Bouraoui, Hamza Benyahia. Effect of carbon nanotubes on the in-plane dynamic behavior of a carbon/epoxy composite under high strain rate compression using SHPB. Smart Materials and Structures, 2020, 29 (8), pp.085012. 10.1088/1361665X/ab83cd . hal-02924116

HAL Id: hal-02924116

https://hal-ensta-bretagne.archives-ouvertes.fr/hal-02924116

Submitted on 16 Jun 2021

HAL is a multi-disciplinary open access archive for the deposit and dissemination of scientific research documents, whether they are published or not. The documents may come from teaching and research institutions in France or abroad, or from public or private research centers.
L'archive ouverte pluridisciplinaire HAL, est destinée au dépôt et à la diffusion de documents scientifiques de niveau recherche, publiés ou non, émanant des établissements d'enseignement et de recherche français ou étrangers, des laboratoires publics ou privés.

\section{(c)(1)}

Distributed under a Creative Commons Attribution| 4.0 International License 


\title{
Effect of Carbon Nanotubes on the In-plane Dynamic Behavior of a Carbon/Epoxy Composite under high strain rate compression using SPHB
}

\author{
M. Chihi ${ }^{1,2}$, M. Tarfaoui ${ }^{1}$, Y. Qureshi ${ }^{1}$, C. Bouraoui ${ }^{2}$, H. Benyahia ${ }^{1}$ \\ ${ }^{1}$ ENSTA Bretagne, FRE CNRS 3744, IRDL, F-29200 Brest, France. \\ ${ }^{2}$ LMS, ENISo, University of Sousse, BP 264, City Erriadh, 4023 Sousse, Tunisia \\ *Corresponding authors: manel.chihi@ensta-bretagne.org mostapha.tarfaoui@ensta-bretagne.fr
}

\begin{abstract}
Fiber reinforced composites have wide structural applications and vast research has been going on to improve their mechanical performance when subjected to quasi-static loading but, study of their dynamic behavior is still underdeveloped. For this reason, scientists have been continuously working on developing methods to improve their dynamic characteristics and addition of nanofillers suchs as Carbon Nanotubes (CNTs) as reinforcement is considered a possible solution for developing future generation high-quality fiber reinforced nanocomposites. In this study, composite specimens are manufactured using Epon 862 Epoxy resin and T300 6k carbon fibers, and each specimen contained different weight percentages of multi-walled Carbon nanotubes (MWCNTs) i.e. $0 \%$ as a reference, $0.5 \%$, and $2 \%$. Specimens were tested experimentally using the Split Hopkinson pressure bar device (SHPB) under different impact pressures to examine their dynamic response and damage behavior at high strain rates. During the dynamic compression tests, a high-speed camera was used to monitor and record the damage kinetics. The experimental characterization showed that the integration of CNTs in matrix has greatly influenced the dynamic response and damage mechanism of the Carbon Fiber Reinforced Polymers composite (CFRP). Mechanical behavior of specimens with each percentage demonstrated the enhancement of the mechanical properties and showed the increase of the dynamic characteristics and fracture resistance because of the increase in stiffness of matrix material and interfacial bonding between matix and fiber reinforcement.
\end{abstract}

Keywords: Nanocomposites, Multi-walled CNTs, SHBP, Dynamic behavior, Damage

\section{ABREVIATION}

\begin{tabular}{|l|l|}
\hline CNTs & Carbon Nanotubes \\
\hline MWCNTs & multi-walled CNTs \\
\hline SHPB & Split Hopkinson Pressure bar \\
\hline CFRP & Carbon Fiber Reinforced Polymers \\
\hline HDPE & high-density polyethylene \\
\hline $\boldsymbol{\varepsilon}_{I}(\boldsymbol{t})$ & Incident wave \\
\hline $\boldsymbol{\varepsilon}_{\boldsymbol{T}}(\boldsymbol{t})$ & Transmitted wave \\
\hline $\boldsymbol{\varepsilon}_{\boldsymbol{R}}(\boldsymbol{t})$ & Reflected wave \\
\hline
\end{tabular}




\section{Accepted Manuscript}

\section{Introduction}

In the recent years, exceptional attention has been devoted to the development of nano-particlereinforced laminate composites to enhance their mechanical properties especially the dynamic ones $[1,2]$. Among these nano-particles, Carbon Nanotubes (CNTs) are widely used in key components and structures in applications such as space, aviation, automotive, wind energy and marine industries. CNT nanocomposites can be fabricated either by inserting CNTs into a matrix material such as ceramics [3, 4], metals [5, 6] and polymers [7-15], into fibers only [16] or into both fibers and a matrix [17]. Their unprecedented mechanical, electrical, thermal and structural characteristics, like low density [18], ultra-high strength and stiffness [1921], high aspect ratio, and high electrical and thermal conductivities have unwrapped additional perspectives for multifunctional materials, such as conductive materials with enhanced mechanical properties. Therefore, it is important to examine and evaluate the behavior of these nanocomposites subjected to different kind of loadings (static, dynamic ...) so as to benefit from their use in various domains. Both experimental and computational studies have been conducted to investigate the mechanical performance, the deformation history and the damage scenarios of CNT based nanocomposites under static and quasi-static loadings [22-26], but very few research works have been reported in the literature regarding the dynamic behavior. On the other hand, there are some other recent investigations, which evaluated the dynamic performance of other materials such as polymers, adhesive joints, composites, and nano-fillers reinforced polymers at high strain rates using different techniques. For impact related applications, one of the most fundamental methods used to evaluate the dynamic response of materials at high load strain rate is the Split Hopkinson Pressure Bar
(SHPB) [27-32]. Although there are, many investigations on the dynamic properties of composites material using the SHPB, relatively few ones have been realized for the polymer reinforced with CNTs. For example, Al-Lafi et al. [33] had studied the performance of high-density polyethylene reinforced with Multi walled CNTs (HDPE/MWCNTs) composite at a high strain rate up to $10^{4} s^{-1}$ using the SHPB device. The experimental characterization showed an increase in toughness. However, the incorporation of MWCNTs did not lead to the increase in yield stress. This could be demonstrated by the rise in the energy dissipation because of the more crack formation in MWCNTs/HDPE composites.

For composites reinforced with CNTs, recent studies have been performed under low velocity impact using Taylor impact tests [34-35]. Their results showed a notable influence of CNTs on the mechanical properties and damage modes of composites. In spite of the potential applications of CNT-reinforced composites to dynamic extremes, research papers concentrating on experimental investigations on such materials under high strain rates have been almost absent. Recently, some researchers had reported their work regarding this area by using the SHPB. For instance, Bie et al. [36] evaluated the dynamic fracture of three different types of MWCNTs/epoxy composites and their neat epoxy subjected to high strain-rate loadings $\left(10^{5}\right.$ $\left.s^{-1}-10^{6} s^{-1}\right)$. They concluded that the fracture scenarios were influenced by both the strength of CNT-epoxy interfaces and of fiber, in addition to other microstructures like the CNTs laminates interface. The mechanical properties of CNTs reinforced composites and neat epoxy showed a strain-rate dependency i.e. the dynamic tensile strength and fracture toughness increased as the strain rate augmented. 
The object of this study was to investigate the influence of integrating different weight percentages of CNTs on the dynamic compressive behavior of CFRP composites at high strain rates. These specimens were subjected to in-plane (IP) dynamic loading using the SHPB device. These samples were manufactured with mass fractions of $0 \%$ as reference, 0.5 , and $2 \%$ and then, they were tested under dynamic compression at four impact pressures i.e. $1.4,1.6,1.8$ and 2 bars. This work will help to

\section{Material and Manufacturing process}

The polymer used in this study was a low viscosity liquid epoxy resin, Epon 862 (Diglycidyl Ether of Bisphenol F), acquired from Momentive Specialty Chemicals Inc. (Cleveland, OH, USA). The carbon fiber was provided by Hexcel Company and Multiwalled carbon nanotubes (MWNTCs) were produced by nanocyl Belgium Company, they were understand the dynamic response and damage behavior of this kind of multi-functional materials because as mentioned earlier, most of the investigations focused on their performance under quasi-static solicitations and some studies require to demonstrate their dynamic performance. The aim is to quantify the contribution of nano additives on the breaking strength of nanocomposites under the action of a dynamic compression.

synthesized with no surface functionalization; they had an average diameter of $10 \mathrm{~nm}$ and length of 1.5 $\mu \mathrm{m}$. Mechanical properties of each constituent are listed in table 1.

Table 1. Material properties.

\begin{tabular}{ll}
\hline Carbon fiber & \\
\hline E11 $(\mathrm{GPa})$ & 230 \\
E22 $(\mathrm{GPa})$ & 15 \\
E33 $(\mathrm{GPa})$ & 15 \\
v12 & 0,28 \\
v13 & 0,28 \\
v23 & 0,28 \\
G12 $(\mathrm{GPa})$ & 15 \\
G13 $(\mathrm{GPa})$ & 15 \\
G23 $(\mathrm{GPa})$ & 15 \\
\hline
\end{tabular}

Figure 1 show SEM and AFM characterization of CNTs in epoxy resin at micro and nano-scales, Figure 1. The multiwall nanotubes were tube-shaped materials and considered as long curved cylindrical fibers (snake-like shapes). The CNTs are randomly distributed into matrix, Figure 1a. Atomic force microscopy (AFM) of CNTs shown the fiber shape, see figure $1 \mathrm{~b}$. 


\section{Accepted Manuscript}

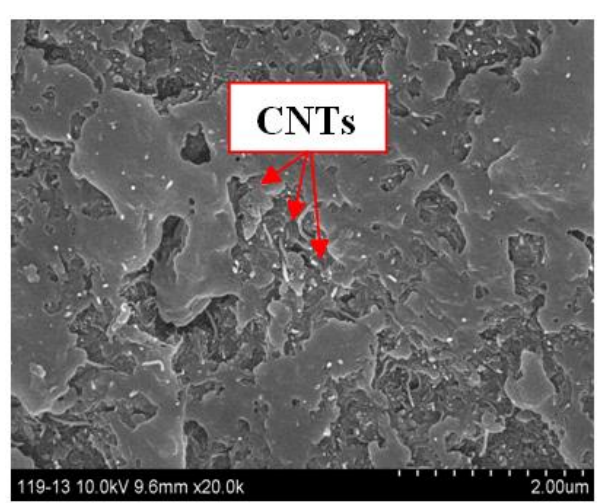

(a) SEM morphology of CNTs into Epoxy

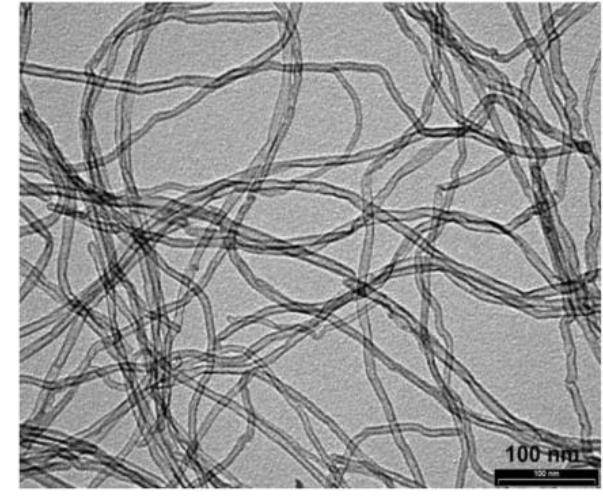

(b) AFM morphology of CNTs into Epoxy

Figure 1. Morphology of multiwall CNTs at micro-scale and nano-scale.

The fabrication of the nanocomposites consisted of first, dispersing CNTs in the polymer matrix, varying the weight fraction of MWNTCs between 0 and $2 \%$, and then, mixing this material using an T 25 digital ULTRA-TURRAX increased shear laboratory mixer for a total of $30 \mathrm{~min}$ at $2000 \mathrm{rpm}$. Afterwards, an ultrasonic path was also used; and the mixed material was further processed in a Lehmann Mills three-roll mixer to guarantee a homogeneous dispersion of CNTs (Figure 2), the film with $120 \mu \mathrm{m}$ in thickness containing CNTs is manufactured using film line, Figure 3a. The reinforced epoxy was introduced with the 5 HS (satin) T300 6k carbon fibers fabric, using infusion process, Figure $3 b-3 c$.
The reinforced epoxy resin flowed between the fibers plies; and the press curing condition was set as $200 \mathrm{MPa}$. All panels manufactured consisted of 24 carbon fiber fabric layers interleaved with 25 layers of CNTs/epoxy film to accomplish an overall fiber volume fraction of $50 \%$. The panels were then cooled. SEM characterization was performed to demonstrate the CNTs distribution with $500 \mathrm{~nm}$ resolution. SEM image confirmed random distribution of CNTs with variable length Figure 3d3 e.

Samples with dimensions of $13 \mathrm{~mm} \times 13 \mathrm{~mm} \times 8 \mathrm{~mm}$ were then cut from the prepared specimen plates for out-of-plane compression test on SHPB, Figure 4.

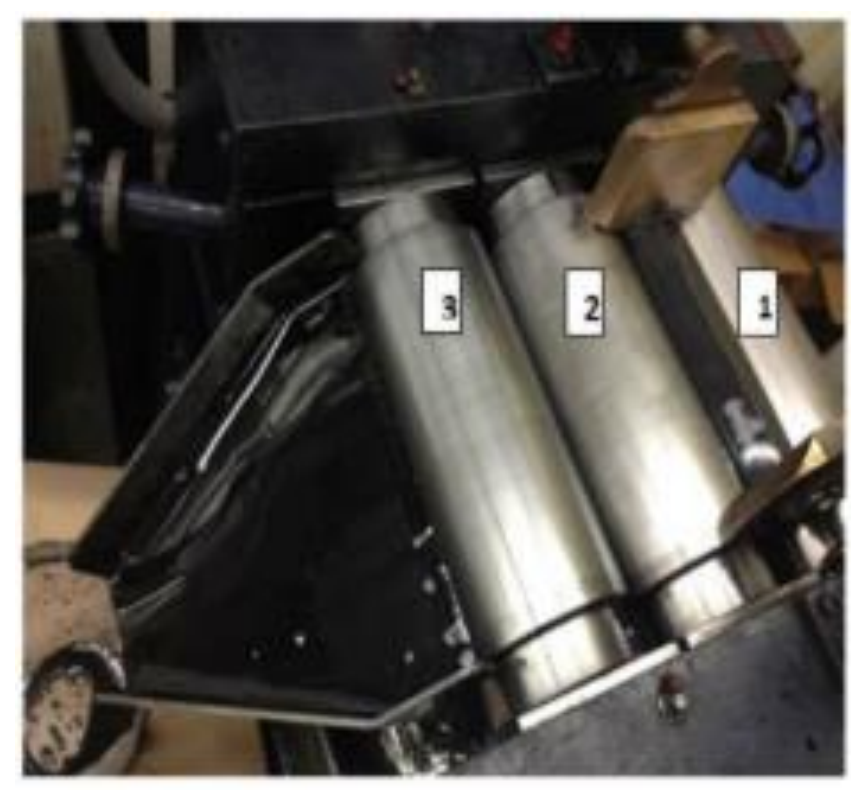

Figure 2. Lehmann Mills three-roll mixer 


\section{Accepted Manuscript}

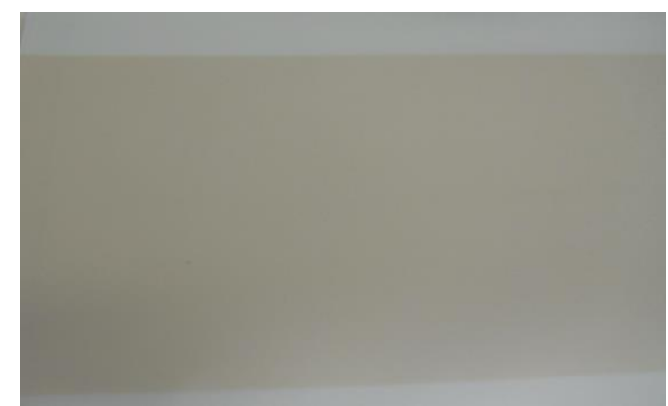

(a) Resin film on white release ply

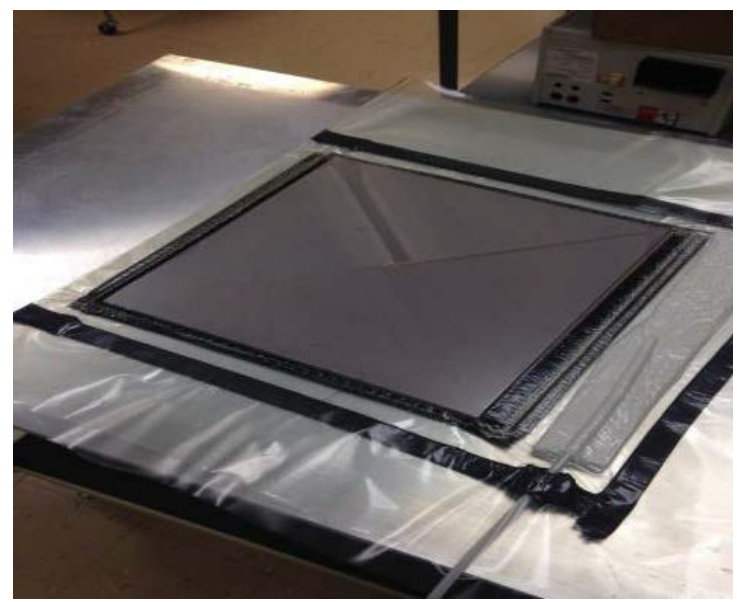

(c) Sample Preparation

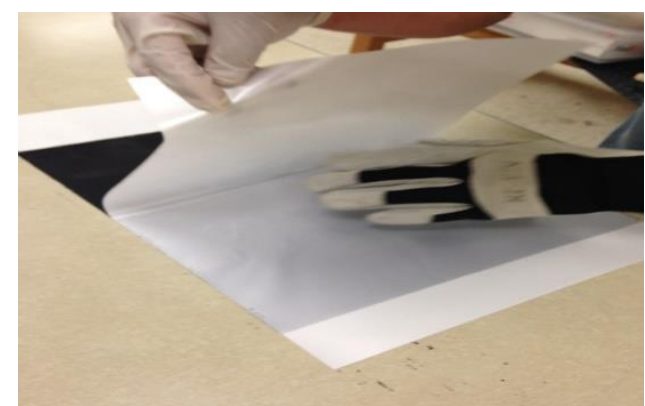

(b) Resin film with nano-additives between two release plies

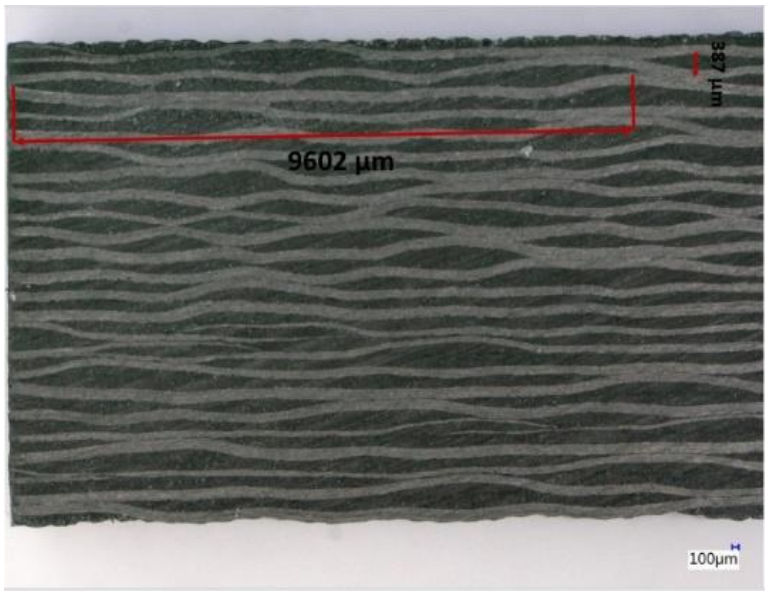

(d) SEM of cross section of the sample

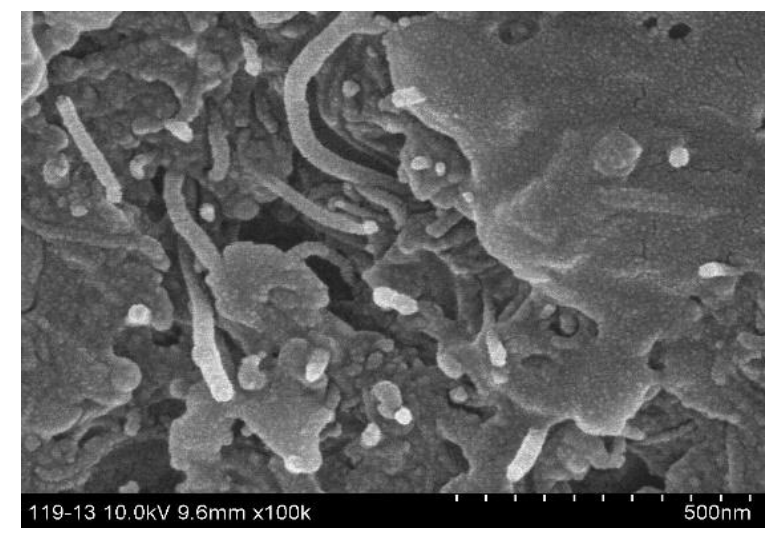

(e) CNTs distribution

Figure 3. Manufacturing steps 


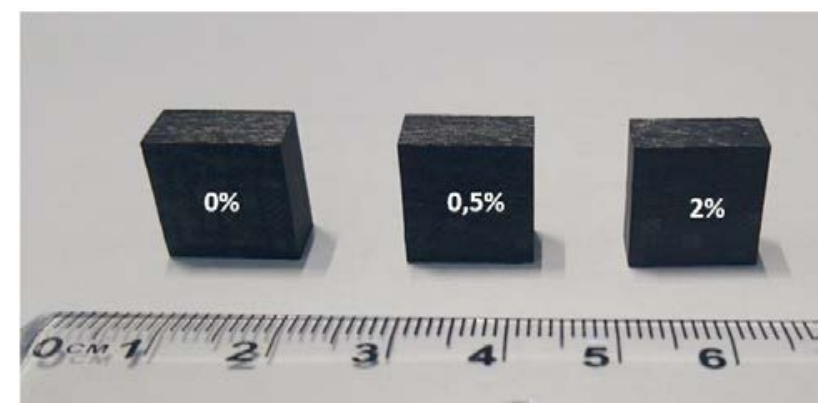

Figure 4. Specimens with different percentages dedicated to dynamic compression tests

\section{Test procedure}

The in-plane dynamic compressive tests were conducted on a SHPB setup in order to investigate the composite behavior under high strain rates loading. Striker, incident and transmitted bars were the SHPB apparatus main components, as shown in Figure 5. Specimens were placed one by one for each test between the incident/input and the transmitted/output bars with no attachments because additional interfaces could cause perturbations during measurements [37].

A compressive incident wave $\varepsilon_{I}(t)$ was generated when a striker bar impacted the free end of the input bar and travelled across the latter until it got to the bar-specimen interface. Once the specimen was hit by the incident wave, it was split into two parts. One part was transferred to the output bar as a compressive pulse $\varepsilon_{\mathrm{T}}(\mathrm{t})$, and the other part was reflected back to the input bar as a tensile pulse $\varepsilon_{R}(t)$. These three waves $\varepsilon_{I}(t), \varepsilon_{R}(t)$ and $\varepsilon_{T}(t)$ were measured using strain gauges mounted at the middle of each pressure bar and a digital oscilloscope was used for data acquisition. During the dynamic compressive tests, the pressure was varied to adjust the striker velocity and to attain a variety of incident load magnitudes. The dynamic characteristics such as strain rate vs. time, stress vs. strain were obtained by processing the recorded data using Maple Software algorithm with fast Fourier transformation (FFT).

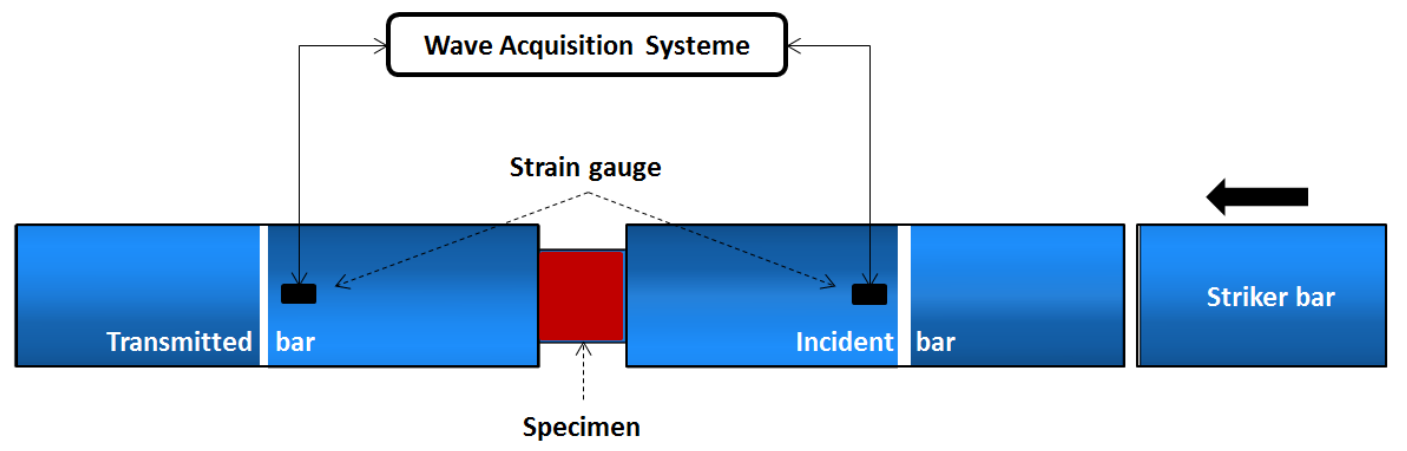

Figure 5: Split Hopkinson Pressure Bar Setup 


\section{Experimental results}

\subsection{Characterization of mechanical behavior under dynamic compression}

The signals received from the experimental setup of bars during the dynamic compression test showed that the incident and transmitted waves were compressive, and the reflected wave was tensile, Figure 6a-6b. These results show the example of two tests performed for specimens with $0 \%$ at pressures of 1.4 bar (Non-damaging test) and 2 bar (Damaging test) respectively. The two results demonstrated the reproducibility of the mechanical behavior of the specimens at each pressure and the behavior of the incident, transmitted and reflected waves showed that the peak of each signal depended significantly on the velocity of striker bar at respective pressure. In addition, the results in both sets of tests showed that the strain rate also known as damage rate of a specimen was affected by the applied pressure. Initially, it was increased rapidly to achieve the maximum peak then decreased however, it remained constant and had negative drop showing the spring back behavior of the specimen for 1.4 bar but there was a secondary increase in the behavior for the 2 bar which is the principle characteristic behavior of these results. The second peak with the short duration of transmitted pulse in strain vs. time, velocity vs. time and strain rate vs. time demonstrated the presence of macrodamage in the nanocomposites at 2 bar [38] (Figure 6d-6f), while the specimens tested at 1.4 bar showed elastic response without any permanent damage when subjected to in-plane dynamic compression, Figure 6c-6e. Moreover, the stress strain behavior of the specimens tested at 1.4 bar showed the elastic-plastic deformation and recovery of elastic strain, Figure $6 \mathrm{~g}$. However, the stress strain behavior of the specimens tested at 2 bar showed the failure of the specimen with the presence of permanent damage without any strain recovery, Figure $6 \mathrm{~h}$. 
Accepted Manuscript

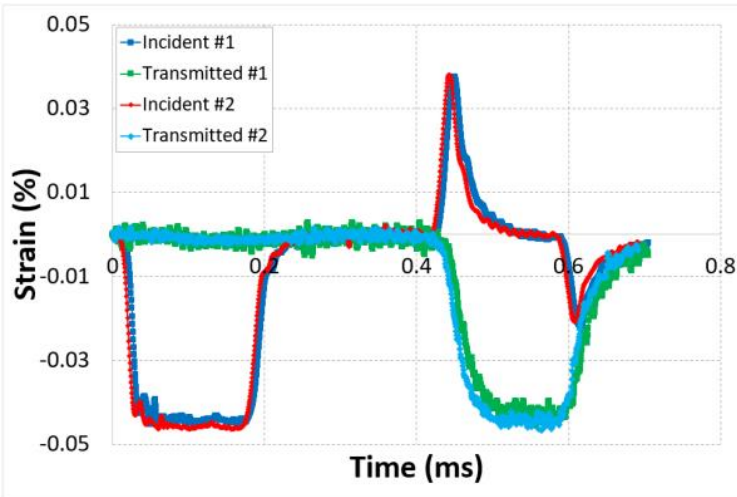

(a)

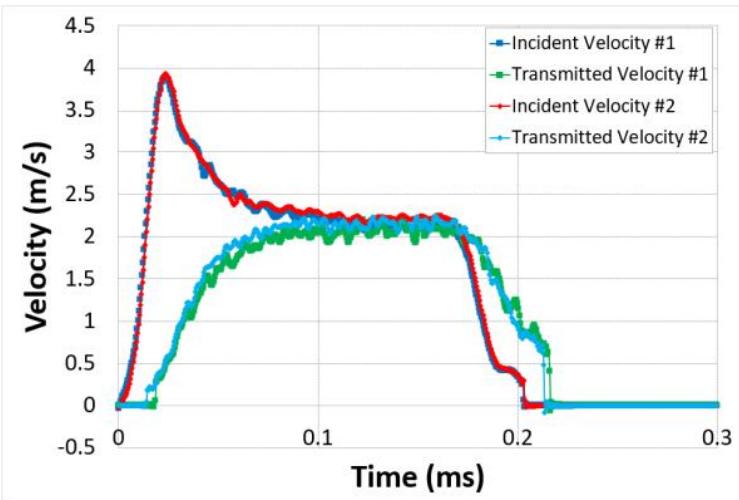

(c)

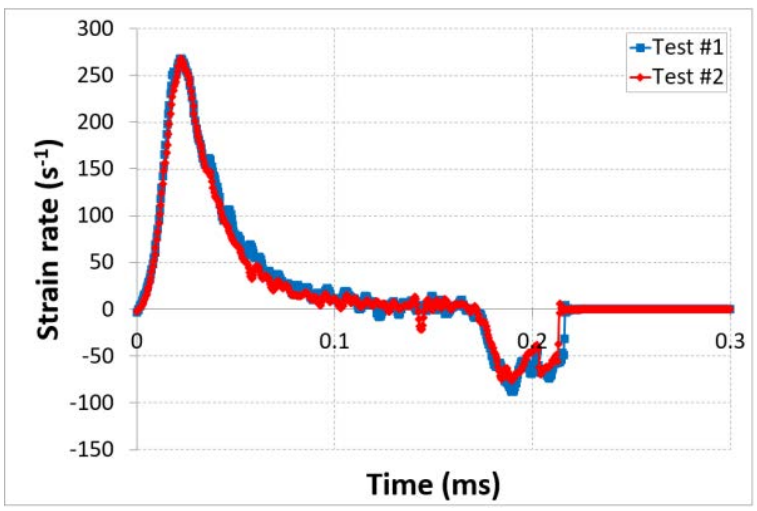

(e)

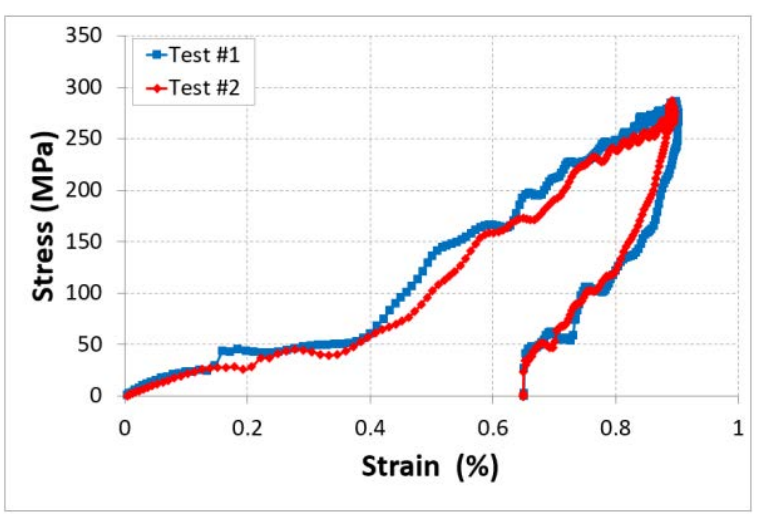

(g)

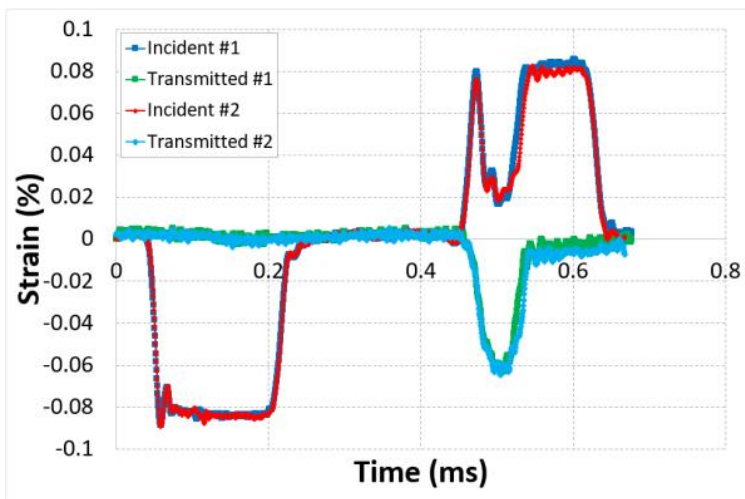

(b)

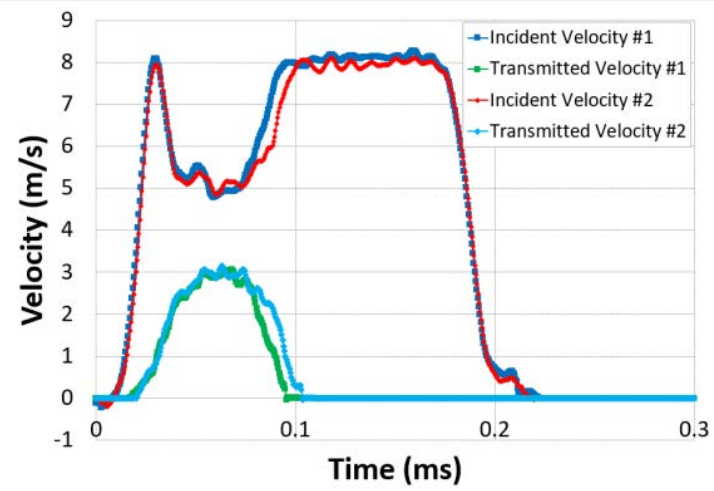

(d)

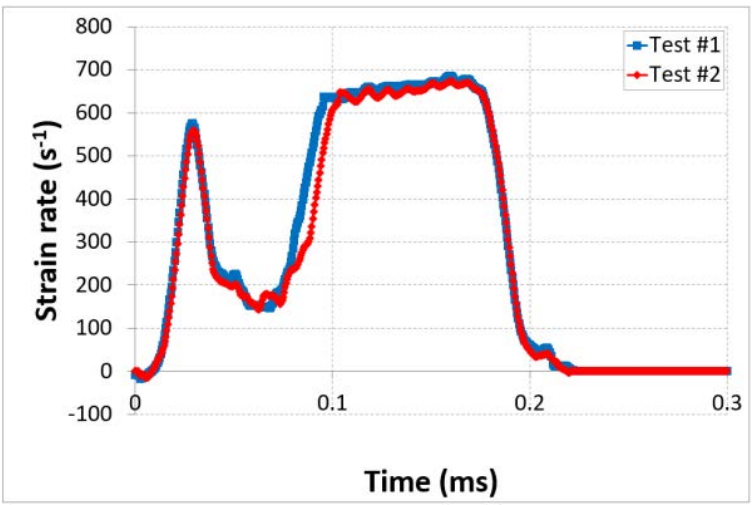

(f)

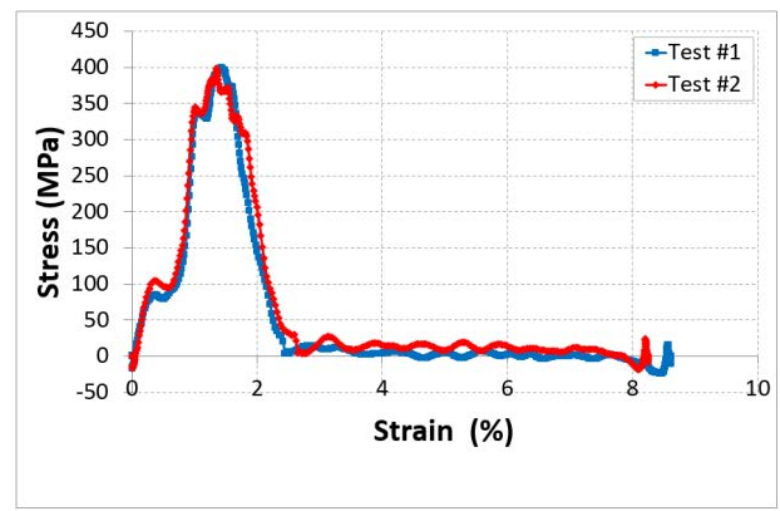

(h)

(A) $\mathrm{P}=1.4$ bar

(B) $\mathrm{P}=2$ bar

Figure 6: Dynamic parameters for two different impact pressures, $0 \%$ NTCs 


\section{Accepted Manuscript}

\subsection{Effects of CNTs on dynamic behavior of nanocomposites}

The composite samples with $0 \%, 0.5 \%$ and $2 \%$ of CNTs were tested under dynamic compression test at four different impact pressures i.e. 1.4, 1.6, 1.8 and 2 bar and results showed that integration of CNTs in CFRP composite played a vital role in improving its dynamic characteristics. Samples tested at 1.4 and 1.6 bar showed only elastic plastic deformation with all percentages, Figure 7a-7b. The negative drop in the strain rate behavior of all these samples demonstrated the rebound effect. Moreover, it was observed that elastic deformation was becoming more dominant with an increase of CNT wt $\%$ at both pressure bars i.e. 1.4 and 1.6. This increase in elastic deformation showed that the material is becoming stiffer and more resistant to permanent damage specific to these pressures. Tests performed at higher pressures i.e. 1.8 and 2 bar showed introduction of permanent damage in samples, Figure $7 \mathrm{c}-7 \mathrm{~d}$. Test performed at 1.8 bar showed that introduction of CNTs improved the damage characteristics of CFRP composites under dynamic compression. The sample with $0 \%$ showed maximum damage and failure of sample with the presence of maximum second peak. Increasing the wt. $\%$ of CNTs up to $0.5 \%$ resulted in decrease in the quantity of macro damage while sample with $2 \%$ CNTs resulted in elastic plastic deformation only without any macrodamage because of the absence of second peak which characterizes the permanent macro damage [38], Figure 7c. All three samples tested at 2 bar showed the presence of permanent damage however, the addition of CNTs reduced the area of second peak suggesting presence of less permanent damage, Figure $7 \mathrm{~d}$. In addition, another interesting phenomenon observed was the delay in the beginning of second peak, which justified the delay in the initiation of permanent macro damage [39]. 


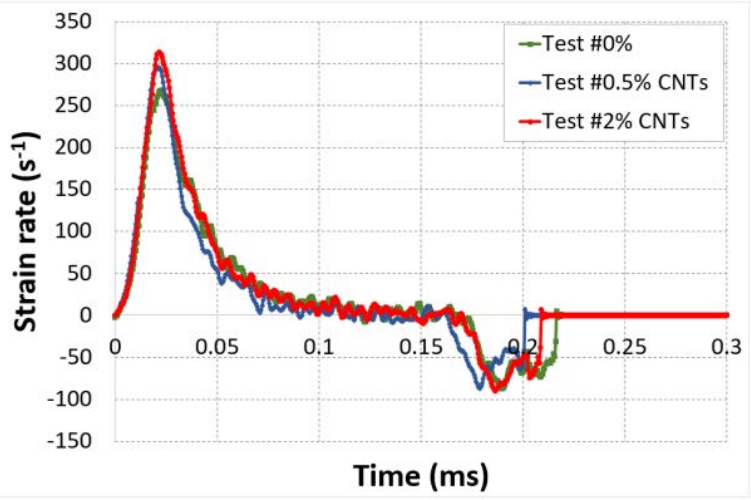

(a) 1.4 bar

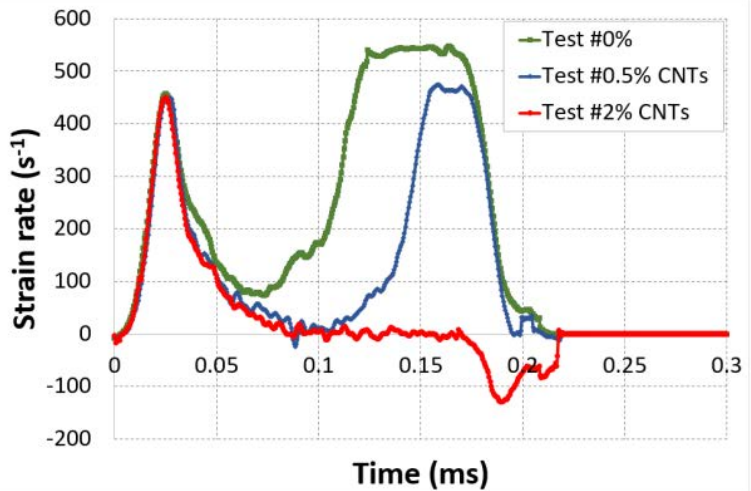

(c) $1.8 \mathrm{bar}$

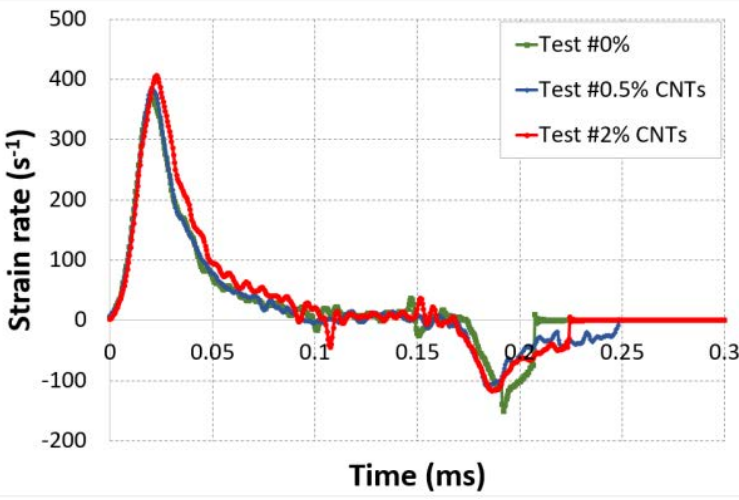

(b) 1.6 bar

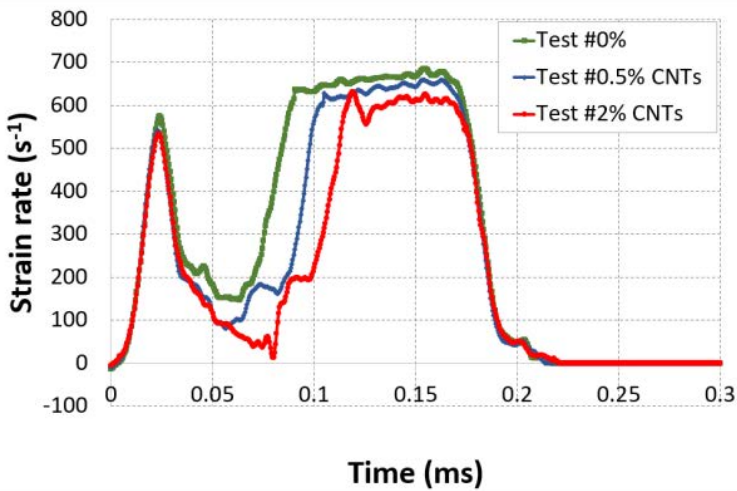

(d) 2 bar

Figure 7: Strain rate vs. time for different mass fraction

Figure 8 gives the behavior laws of the different materials for the different impact pressures. It can be noted here that:

- $\quad$ The behavior for low impact pressures (1.4 and 1.6 bar) is almost similar. However, it should be noted that the dynamic behavior of the three types of specimens is different: dynamic modulus (initial stiffness), maximum stress and maximum deformation.

- For $\mathrm{P}=1.8$ bar, we have an appearance of macroscopic damage for the $0 \%$ and the $0.5 \%$ whereas for the $2 \%$ we still have the elastic springback with a slight plasticity.

- $\quad$ Still for the pressure of 1.8 bar, the damage kinetics are different for the $0 \%$ and $0.5 \%$; this is visible on the 2nd part of the curve (discharge)

- For $\mathrm{P}=2$ bar, there is macroscopic damage for the 3 types of specimen but the damage history is different.

Moreover, stress-strain behavior of samples with $0 \%, 0.5 \%$ and $2 \%$ CNTs at each pressure showed similar overall behavior because of the same composition of the sample which consisted of epoxy and carbon fiber and the only difference was the addition of CNTs in different $\mathrm{wt} \%$ in respective samples. Addition of CNTs improved the stressstrain behavior of CFRP composites in each pressure moreover, increasing CNTs to 2 wt.\% further enhanced the stress-strain performance of CFRP composites at all said pressures by reducing the 
amount of plastic deformation (non-damaging tests), Figure $8 \mathrm{a}-8 \mathrm{~b}$, or the permanent macro damage (damaging tests), Figure 8c-8d. Addition of CNTs also resulted in improvement of elastic stress-strain behavior of CFRP composites at pressures 1.4 and 1.6 bar. However, CFRP composites showed failure at 1.8 and 2 bar and addition of CNTs resulted in reduction of permanent failure. Furthermore, it was

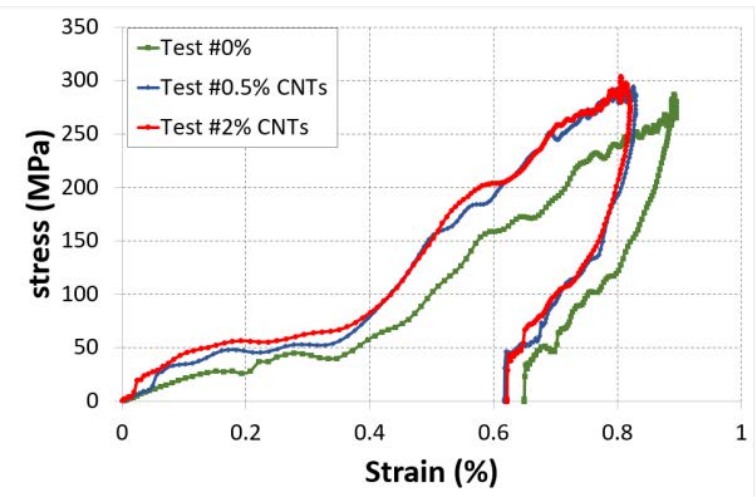

(a) 1.4 bar

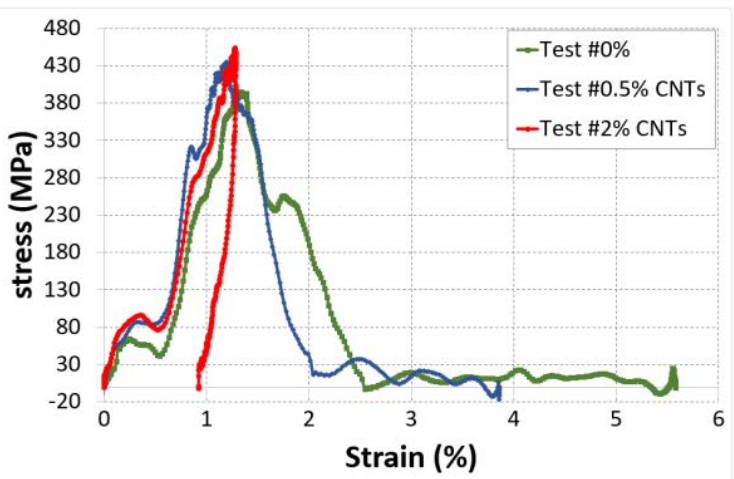

(c) $1.8 \mathrm{bar}$ clear that the maximum strength of the material was greatly improved which showed that with the addition of CNTs the material became stiffer and more resilient and could absorb more impact energy [40]. The effect of CNTs on the modification of mechanical behavior of the material was distinct in tests performed on 1.8 bar where addition of $2 \%$ of CNTs resulted in absence of permanent deformation.

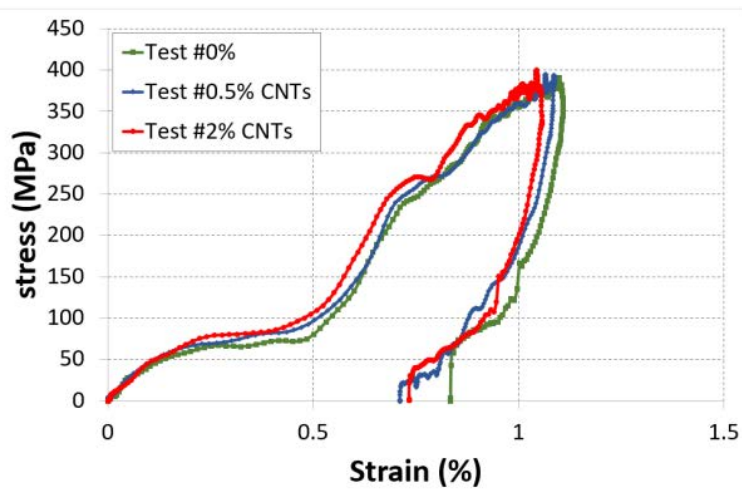

(b) 1.6 bar

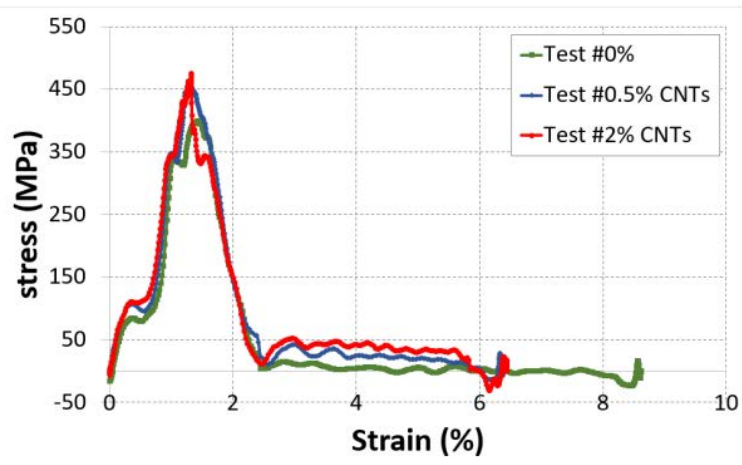

(d) 2 bar

Figure 8: Stress vs. Strain for different mass fraction

In addition, the maximum strain deformation rate and maximum strength were also demonstrated using phenomenological laws that could account the effect of impact pressure thus, providing a framework to model the dynamic behavior of nanocomposites under impact for design optimization purposes, Figure 9. Average of all results at each impact pressure was calculated with error sensitivity curve. Evolution of the strain rate was demonstrated by the logarithmic relation with the change of impact pressure with curve fitting of accuracy more than $98 \%$. Results showed that the strain rate became more prominent by increasing the impact pressure for CFRP composites with $0 \%$. 


\section{Accepted Manuscript}

However, introduction of CNTs reduced the logarithmic evolution of strain rate and the curves became more linear for example, CFRP sample with $2 \%$ showed curve fitting accuracy of $99.68 \%$, Figure 9a. Similarly, evolution of maximum stress behavior was demonstrated by parabolic relation with the change of impact pressure with curve fitting accuracy of $94 \%$. Results showed that maximum strength was increasing with the increase of impact pressure for samples with $0 \%$ CNTs. However, introduction of CNTs not only improves the maximum strength of the sample but also achieved curve fitting accuracy of $100 \%$, Figure $9 \mathrm{~b}$. This showed that introduction of nanofillers such as CNTs in composites not only improves their dynamic properties but also improves the dependency of these dynamic properties on the dynamic loadings for design optimization purposes. 


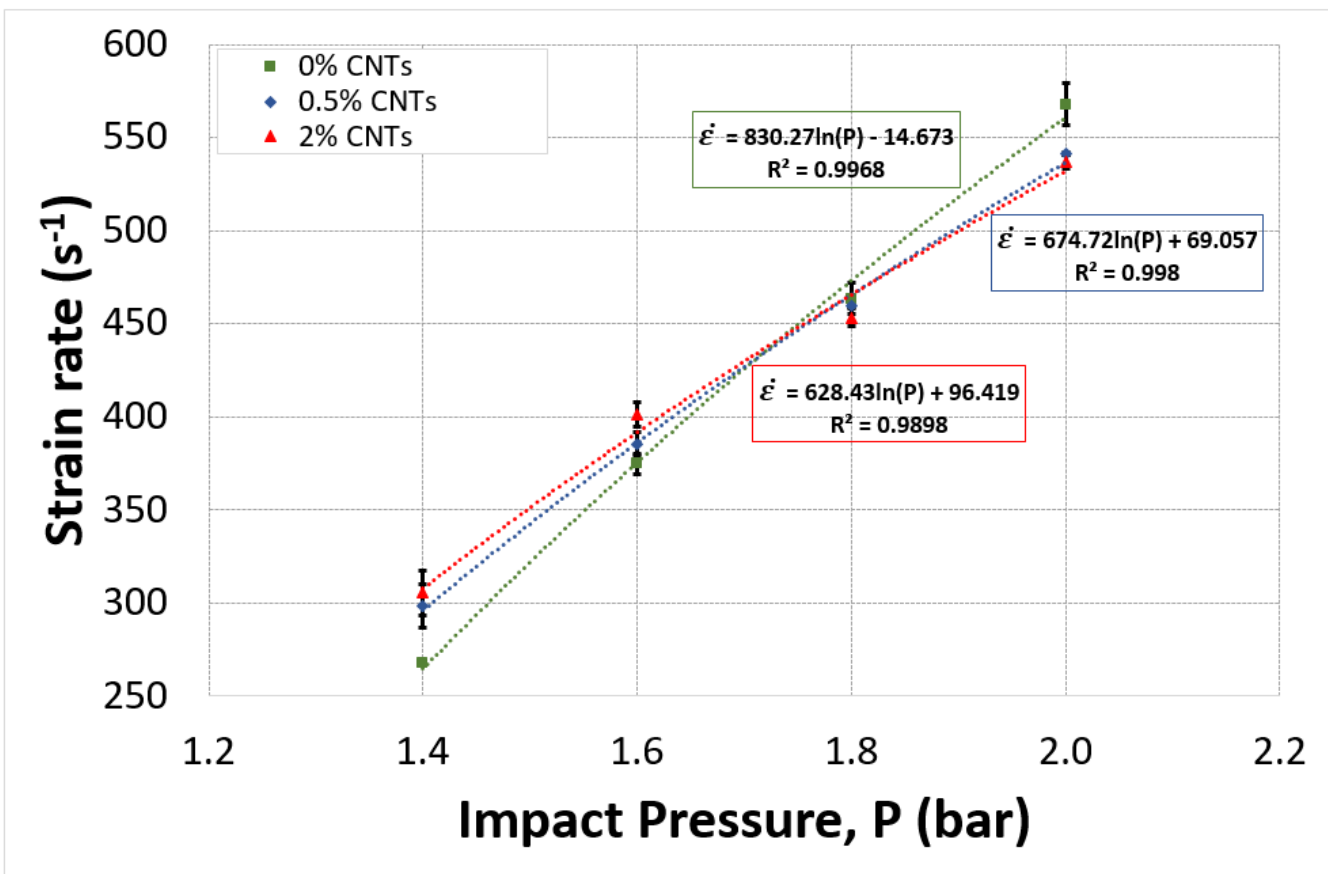

(a) Evolution of strain rate at different impact pressure

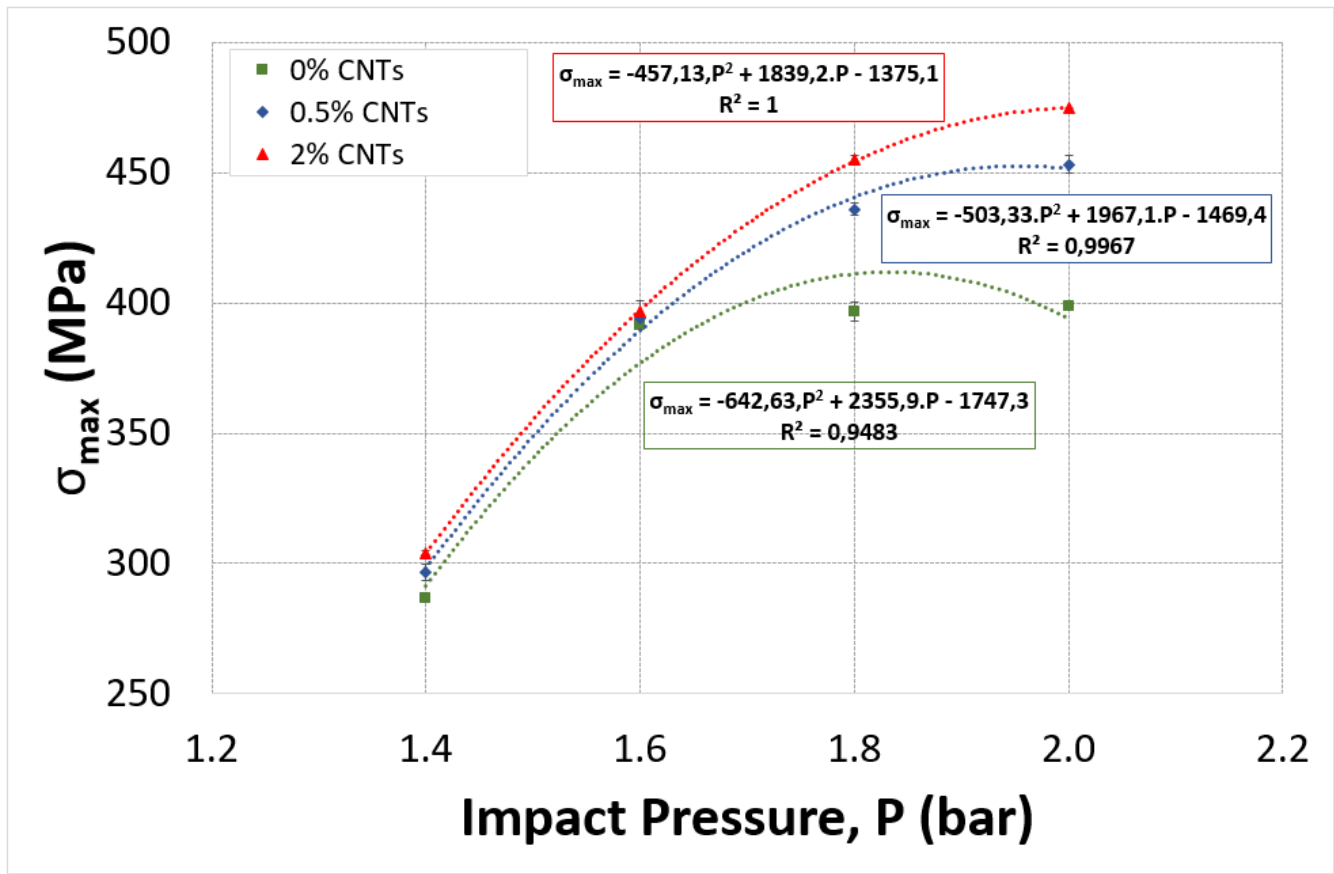

(b) Evolution of Maximum stress at different impact pressure

Figure 9: Evolution of dynamic properties with respect to impact pressure. 


\section{Accepted Manuscript}

\subsection{Comparison of deformation behavior of nanocomposites with and without damage}

Comparison of stress and strain rate of all samples at 1.8 bar and 2 bar showed the correlation of different stages dynamic behavior with and without damage respectively. Tests conducted at 1.8 bar for sample with $2 \%$ CNTs showed elastic plastic deformation in both stress and strain deformation rate curves, Figure $10 \mathrm{~A}(\mathrm{c})$. The initiation of stress and strain deformation rate occurred at the same time and when strain deformation rate was maximum, the sample achieved its maximum elastic strength. After achieving the maximum strain rate, the sample recover the elastic deformation and, at the same time, the maximum strength was achieved and the region was stabelized. Afterwards, when strain rate achieved rebound effect showed by negative drop, the strength of the sample returned back to zero. This rebound effect ( springback) described the recovery of the sample from the elastic deformation and returning to original position as before the impact. This demonstration of results confirm elastic deformation of the sample with some permanent deformation but without any presence of macrodamage. Damaged tests conducted at 1.8 and
2 bar, Figure 10A (a)-(b) \& 10B showed the similar comparison of strain rate and maximum strength for all samples but with the introduction of second peak which charactrized the presence of macrodamage. The initiation of stress and strain deformation rate occurred at the same time and when strain rate was maximum, the sample achieved its maximum elastic strength. After achieving the maximum strain rate, the sample initiated the permanent strain rate by the introduction of second peak and at the same time sample achieved its maximum strength. Afterwards, when the strength started to decrease, the second peak of strain rate started to increase. This phenomenon confirmed the presence of macrodamage thus, resulting in degradation of the material. When the sample achieved maximum second peak and was stabelized, the strength of the material was reduced to zero confirming the final failure of the samples. This will be discussed in more detail in the next section. 


\subsubsection{For Samples without damage (2\% CNTs) tested at 1.8 bar, Figure 10A(c)}

- Zone 1: Initiation and fast evolution of strain rate and maximum stress, which could be interpreted by the self-placement of the sample between the bars and generation of parallel contact between the bars and faces of the samples was not $100 \%$ which coulde be justify the almost zero stress in the zone.

- Zone 2: Once perfect contact was ensured, material strength generated a drop in strain rate and an increase in maximum stress.

- Zone 3: After the acheivement of maximum value of stress and strain rate was zero, both regions

\subsubsection{For Samples with damage tested at 2 bar, Figure $10 A(a)-(b) \& 10 B$}

- Zone 1: Similar behavior and observations as in zone 1 of the tests without any damage.

- Zone 2: Similar behavior and observations as in zone 2 of the tests without any damage

- Zone 3: After the acheivement of maximum value of stress and minimum value of strain rate, both regions became stabelized similar to zone 3 of tests without any damage however the time duration of the zone was reduced.

- Zone 4: In this zone, the second peak of strain rate was initiated and was evolving rapidly at the same moment as the maximum stress started to decrease, became stabelized which ensured that the sample reached maximum elastic compression strain under maximum stress.

- Zone 4: In this zone, there was a negative drop in the strain rate whereas the maximum stress started to decrease, this confirmed the springback action and specimen started to relax

- Zone 5: In this zone, the maximum stress and strain rate return to initial condition and reached zero value.

this confirmed the initiation of macroscopic damage in the specimen.

- Zone 5: In this zone, the maximum stress achieved zero value while strain rate rached maximum second peak and became stabelized which confirmed the degradation of the samples.

- Zone 6: In this zone, the second peak started to decrease rapidly and achieved zero value while maximum stress further stabelized the previous region i.e. zero value. This confirmed the total rupture of the sample.

- Zone 7: In this zone, the stress and strain rate return to initial condition and reached zero value. 

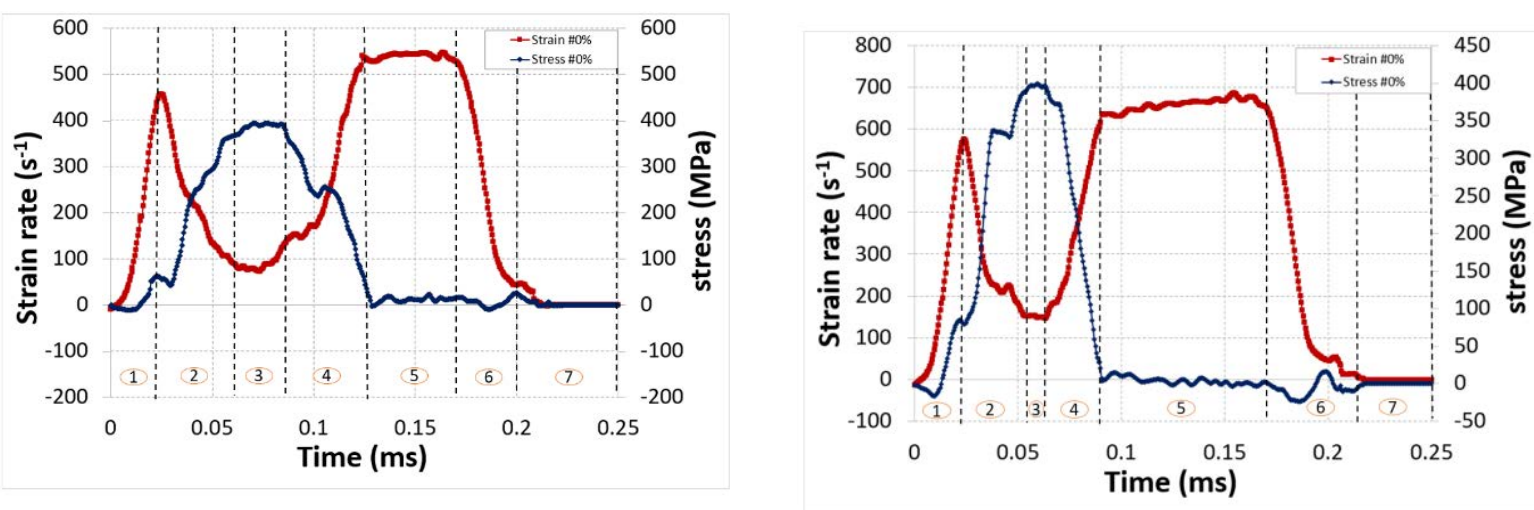

(a) $0 \%$
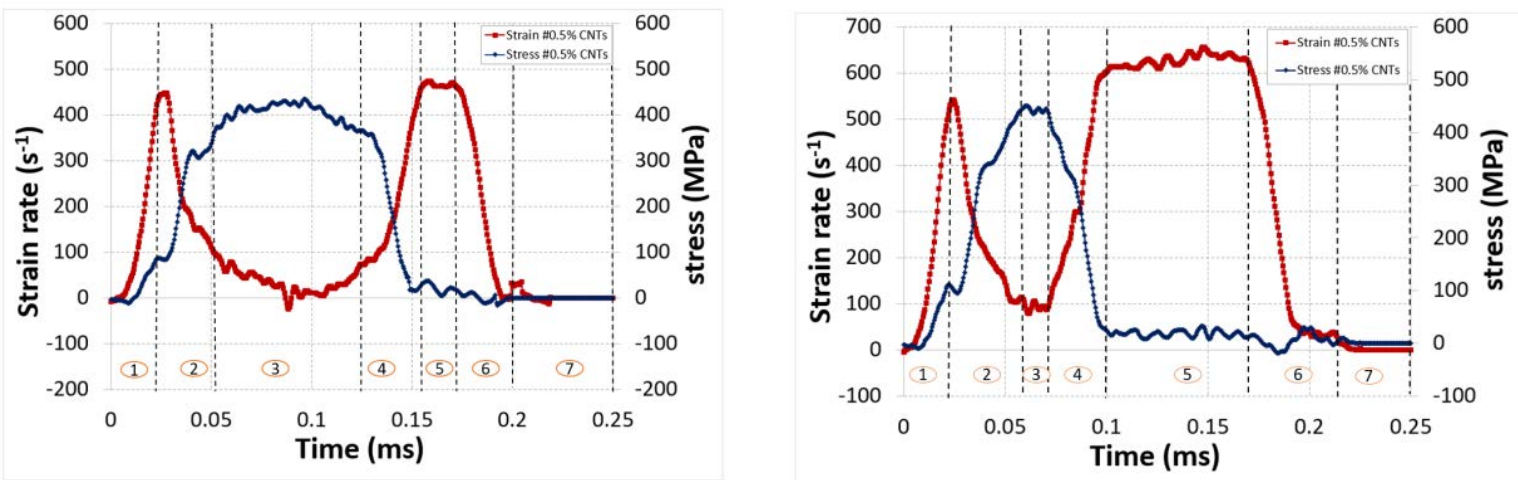

(b) $0.5 \%$
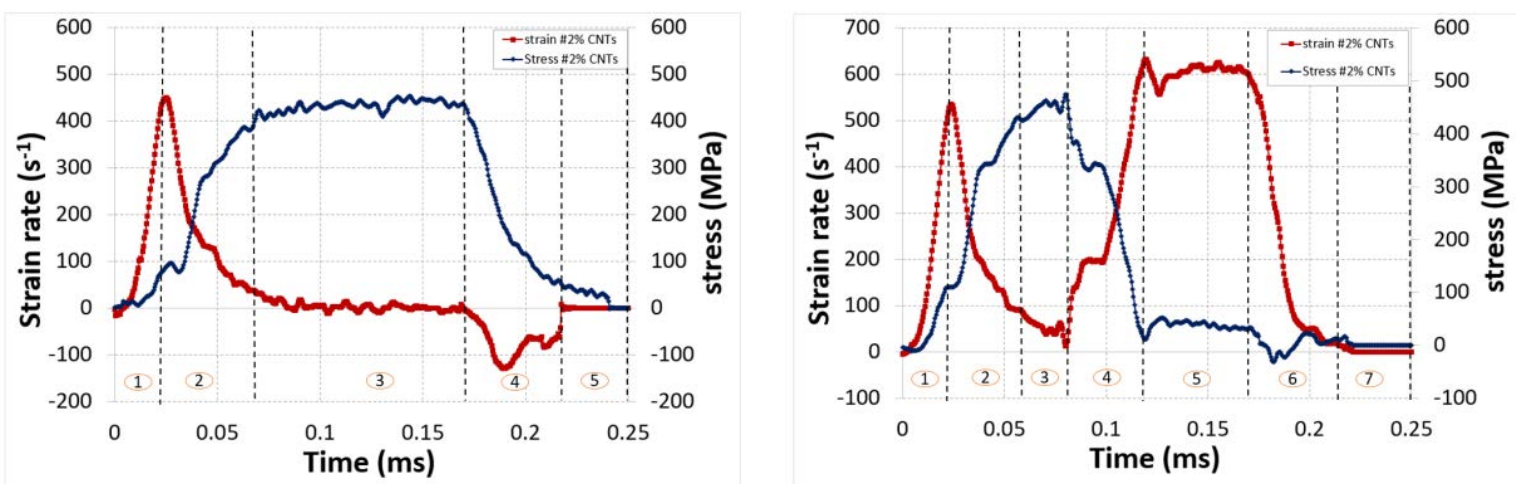

(c) $2 \%$
(A) $\mathrm{P}=1.8$ bar
(B) $\mathrm{P}=2$ bar

Figure 10: Comparison of stress and strain rate, during the dynamic compression test at 1.8 and 2 bar respectively with the introduction of CNTs. 


\section{Accepted Manuscript}

To further understand the deformation and failure mechanism of the samples, a high-speed camera was used for each test to follow the evolution of damage,. Figures 11 and 12 show the rapid camera images for samples with $0 \%, 0.5 \%$ and $2 \%$ tested at 1.8 and 2 bar. For each test, four high speed camera images were presented to demonstrate (1) the initial state of specimens at $\mathrm{t}=0 \mathrm{~s}$, (2) the evolution of dynamic compression of the samples at $\mathrm{t}=0.07 \mathrm{~s}$, (3) the permanent crushing within the specimen or spring back phenomenon for samples without macrodamage at $\mathrm{t}=0.15 \mathrm{~s}$ and (4) the final fracture at $0.24 \mathrm{~s}$. The high-speed camera images showed that the introduction of CNTs has improved the final damage performance of the CFRP composites and sample with $2 \%$ did not show any macro damage for 1.8 bars, Figure $11 \mathrm{c}$. In addition, the images for the tests performed at 2 bar confirmed that all the samples showed the presence of macro damage. However, addition of CNTs had reduced the quantity of final macro damage and sample with $2 \%$ presented less propagation of crack and delamination between the layers of composites which confirmed the increase in bonding strength of epoxy with the fibers, Figure 12c. These high-speed camera images of the samples correlated perfectly with the mechanical curves of the tests. This comparison confirmed that the amount of macro damage was reduced greatly at each impact pressure and the dynamic characteristics of the CFRP composites were improved by the addition of CNTs; the amount of macro damage was reduced to zero with the addition of $2 \%$ CNTs at 1.8 bar. The images of fractured samples with $0 \%, 0.5 \%$ and $2 \%$ tested at 1.8 and 2 bar which confirmed the reduction of delamination, intralaminar cracking and debonding of the specimen because of the CNTs. Furthermore, this study showed that addition of CNTs and increasing their percentage upto $2 \%$ showed improvement in the mechanical behavior of the CFRP composites because of increasing the stiffness of matrix material and interfacial bonding between the matrix and fiber reinforcement with uniform dispersion. If there were agglomeration of CNTs in the matrix the mechanical behavior of the nanocomposite would have been different as it could behave as a defect and decrease the mechanical performance of the specimen as demanstrated by Trafaoui et al. [41-43]. 
$\mathrm{t}=0 \mathrm{~s}$
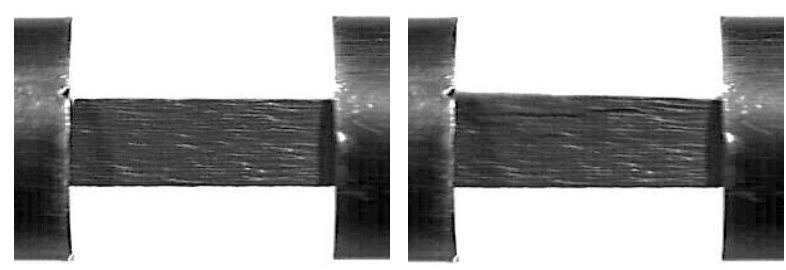

(a) $0 \%$
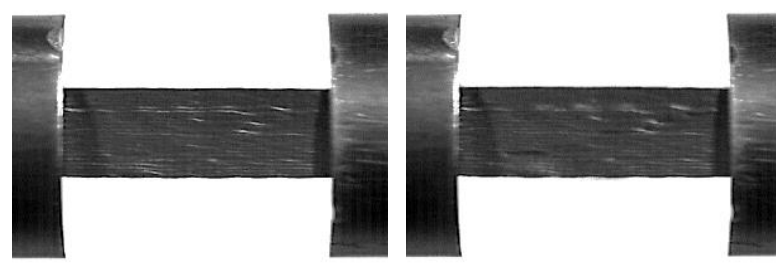

(b) $0.5 \%$
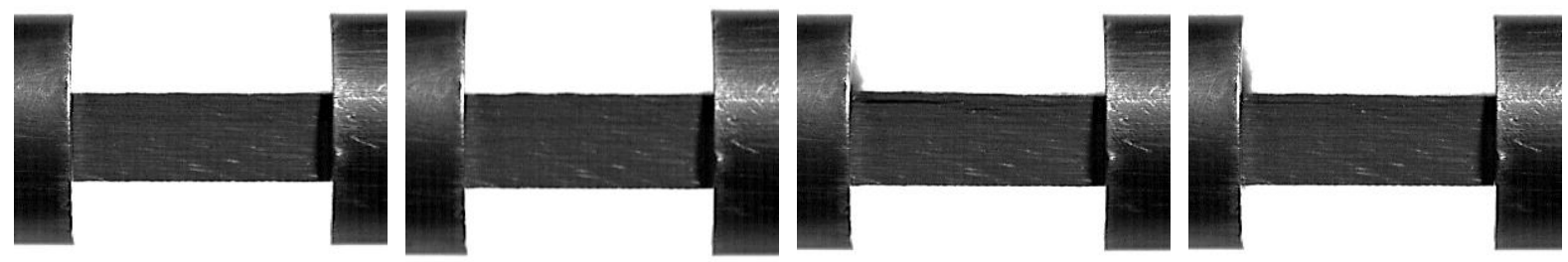

(c) $2 \%$

Figure 11: High-speed camera images of tests performed at 1.8 bar for samples with $0 \%, 0.5 \%$ and $2 \%$ CNTs 
$\mathrm{t}=0 \mathrm{~s}$
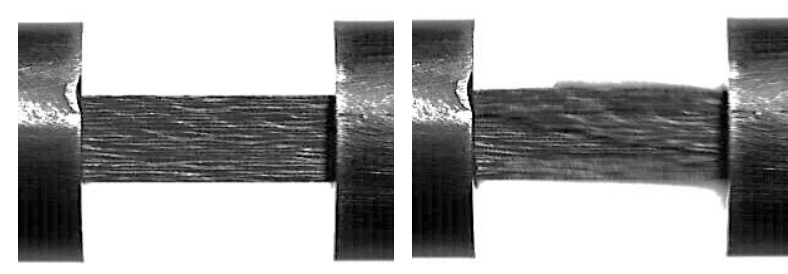

(a) $0 \%$

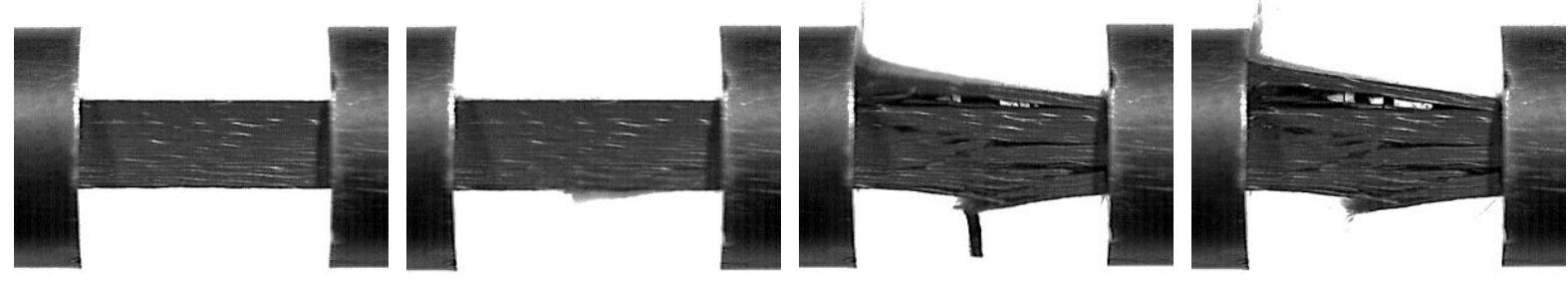

(b) $0.5 \%$
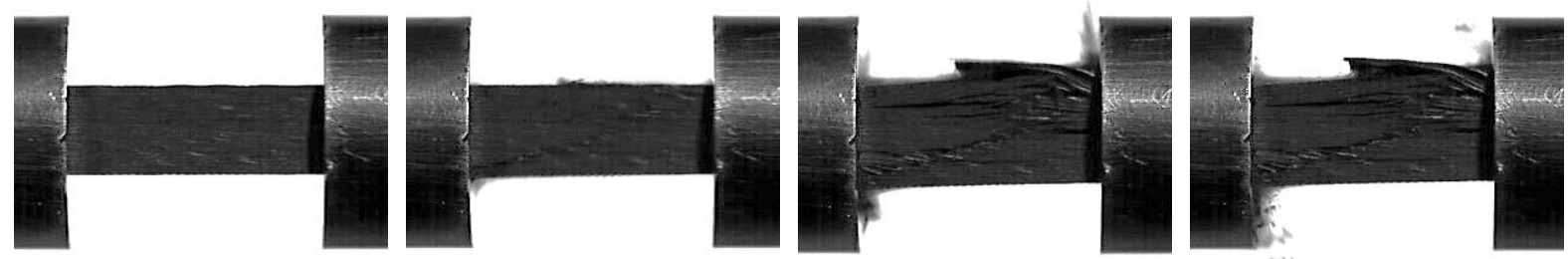

(c) $2 \%$ 


\section{Accepted Manuscript}

\section{Conclusion}

In this investigation, Split Hopkinson pressure bars were used to examine the mechanical behavior of CFRP composites at different impact pressures and to study the effect of introducing CNTs on their dynamic response. samples were prepared with three different weight percentages i.e. $0 \%, 0.5 \%$ and $2 \%$ and were subjected to in-plane dynamic compression at impact pressures 1.4, 1.6, 1.8 and 2 bar. The results showed that the dynamic response of samples at each impact pressure showed good reproducibility in results and addition of CNTs improved the mechanical performance of the CFRP composites under dynamic impact loading. In addition, results confirmed the strong dependency of maximum stress and strain rate of each set of samples on the impact pressures. Addition of CNTs not only showed improvement in the elastic properties of the CFRP composites but also showed reduction in the amount of macrodamage when second peak was present during dynamic compression at higher impact pressure. The high-speed camera images further confirmed the improvement of damage mechanism of these nanocomposites with the introduction of CNTs with the reduction in delamination, intralaminar cracking and crack propagation because of improved adhesion bonding between the matrix and the fiber and because CNTs hindered the crack propagation, which was further, confirmed by the images of fractured samples. This study showed that addition of CNTs have greatly improved the mechanical performance of the CFRP composites under dynamic loading therefore confirming their application in structures subjected to dynamic failure. 


\section{References}

[1] Kolsi L, Hussein AK, Borjini M, et al 2014 Arabian Journal for Science and Engineering 39 7483-7493

[2] Hussein AK, Bakier M, Ben Hamida M, et al 2016 Alexandria Engineering Journal 55 2157-2169

[3] Peigney A, Laurent Ch, Flahaut E, et al 2000 Ceramics International 26 677-683

[4] Peigney A, Flahaut E, Laurent Ch, et al. 2002 Physics Letters 352 20-25

[5] Kuzumaki T, Miyazawa K, Ichinose H, et al 1998 Journal of Material Research 13 $2445-2449$

[6] Xu CL, Wei BQ, Ma RZ, et al 1999 Carbon 37 855-858

[7] Cochet M, Maser WK, Benito AM, et al 2001 Chemical Communications 16 14501451

[8] Jin Z, Sun X, Xu G, et al 2000 Physics Letters 318 505-510

[9] Jin Z, Pramoda KP, Xu G, et al 2001 Chemical Physics Letters 337 43-47

[10] Kumar S, Doshi H, Srinivasarao M, et al 2002 Polymer 43 1701-1703

[11] Lourie O and Wagner HD 1999 Composites Science and Technology 59 975-977

[12] Qian D, Dickey EC, Andrews R, et al 2000 Applied Physics Letters 76 2868-2870

[13] Sandler J, Shaffer MSP, Prasse T, et al 1999 Polymer 40 5967-5971

[14] Shaffer MSP and Windle AH 1999 Advanced Materials 11 937-941

[15] Yoshino K, Kajii H, Araki H, et al 1999 Fullerene Science and Technology 7 695-711.

[16] Garcia E.J, Wardle B.L, Hart A.J, et al 2008 Composites Science and Technology 68 2034-2041.

[17] Warrier A, Godara A, Rochez O, et al 2010 Composites Part A: Applied Science and Manufacturing 41 532-538.

[18] Thostenson ET and Chou T.W 2003 Journal of Physics D: Applied Physics 36 573-82

[19] Yu MF, Lourie O, Dyer MJ, et al 2000 Science 287 637-640

[20] Yu MF, Files BS, Arepalli S, et al 2000 Physical Review Letters 84 5552-5555

[21] Li C and Chou TW 2003 Composites Science and Technology 63 1517-1524

[22] Tarfaoui M, El Moumen A and Lafdi K 2016 Composites Part B: Engineering 103 113121

[23] El Moumen A, Tarfaoui M and Lafdi K 2017 Composites Part B: Engineering 114 1-7

[24] Tarfaoui, M, El Moumen, A, Lafdi, K 2017 Composites Part B: Engineering 112 185195 
[25] Kundalwal, S.I. 2018 Polymer composites 39 4243-4274

[26] Kundalwal, S.I. , Kumar, S 2016 Mechanics of Materials 102 117-131

[27] Tarfaoui M, Neme A and Choukri S 1998 Journal of Composite Materials 43 11371154

[28] Gueraiche L, Tarfaoui M, Osmani H, et al. 2015 Composite Structures 126 145-158.

[29] Arbaoui J, Tarfaoui M and EL Malki Alaoui A 2016 International Journal of Impact Engineering 87 44-54

[30] Arbaoui J, Tarfaoui M and EL Malki Alaoui A 2016 Journal of Composite Materials $503313-3323$.

[31] Shah OR and Tarfaoui M 2017 Composites Part B: Engineering 111 134-142.

[32] Sassi S, Tarfaoui M and Benyahia H 2018 Composite Structures 191 168-179.

[33] Al-Lafi W, Jie J, Sunxi X, et al 2010 Macromolecular Materials and Engineering 295 519-522.

[34] El Moumen A, Tarfaoui M, Lafdi K et al 2017 Composites Part B: Engineering 125 18

[35] Benyahia H, Tarfaoui M, Datsyuk V et al 2017 Composites Science and Technology 148 70-79.

[36] B.X. Bie, J.H. Han, L. Lu et al 2016 Dynamic fracture of carbon nanotube/epoxy composites under high strain-rate loading. Composites Part A: Applied Science and Manufacturing 68 282-288.

[37] Bancroft D 1941 Physical Review Journals Archive 59 588-593.

[38] Tarfaoui M, Choukri S and Neme A 2008 Composites Science and Technology 68 477485

[39] Tarfaoui M, El Moumen A and Lafdi K 2017 Composites Part B: Engineering 112 185195.

[40] A. El Moumen, M. Tarfaoui, O. Hassoon, et al 2018 Applied composite materials 25 309-320.

[41] M. Tarfaoui, K. Lafdi, A. EL Moumen, 2016 Composites Part B: Engineering 103, 15 113-121.

[42] Tarfaoui, M., El Moumen, A., Lafdi, K. 2017 Composites Part B: Engineering 112 185195.

[43] El Moumen, A., Tarfaoui, M., \& Lafdi, K. 2017 Composites Part B: Engineering 114 Pages 1-7. 